cortex, viz. the large ganglionic, the so-called motor cells of the fourth layer, and the smaller cells which exist in vast numbers in the rest of the grey cortex, and he believes that consciousness is correlated with the functions of the smaller cells, and not with the larger ones. I would venture to say that such a belief as that is of course a personal matter, but argument of analogy seems to me to be strongly in favour of this contention. But there is another mode of regarding the anatomical facts just mentioned, and that is the possibility of each being correlated to efferent and afferent functions respectively. Of course, theoretically, we may for many reasons regard the fow large corpuscles as essentially efferent, and the small cells as essentially afferent in function. For myself, I am quite prepared to hear it proved some years later that the smaller cells bave a distinctly sensory aspect, and that the larger cells have a distinctly motor aspect. Until this anucomical problem has been cleared up, we must leave the question entirely open whether the smaller cells are kinæsthetic or not. Dr. Ferrier would say absolutely that they are not; that there is no representation of sensation in this "motor" region, and that therefore the function of these smaller cells is motor. That the whole sectior of the brain cortex in this region is motor, it is very difficult to believe, though such a view is apparently supported by snme very considerable facts. Finally, as regards experimental evidence, enough has been said on that point to avoid adding to it. The only experiments that will show anything are the observations on human beings. Until after small localised portions of that region have been excised, and a reliably large number of such cases have been thoroughly examined and reported, it will be impossible to do more on this problem than admit. its present insolubility.

\title{
Professor HaYcraft.
}

I should like to draw attention to a change which has recently taken place in the views of many physiologists respecting the functions of nerve cells and nerve centres. This change is due, I think, to a more philosophical conception of the development of the brain, and to the introduction of improved technical methods for its histological investigation. I venture to make these remark8, because in my opinion the discussion, as to whether certain regions of the cerebral cortex are motor or sensory; can resolve itself into a statement of what they really are in terms of these newer conceptions. We must remember that the central nervous system in higher animals is interposed between the sensory surfaces of the body and the muscular system, etc. and that the nerrous connec- 
tion between a sensory surface and a muscle forms a loop passing through the brain or cord. In its path this loop is beset with nerve cells, which are spoken of as being sensory or motor cells. As a result of stimulating the skin of an arm, an impulse will pass to the cord and may turn back to a muscle of the same limb. It may, however, make a larger circuit, and pass up to the brain, to the grey matter around the fissure of Rolando, back to the cord, and out to the muscle. In the second case, it passes to the brain, in order that it may be correlated with other impulses passing in other loops belonging to the special senses; for the brain is to be considered strictly as an enlargement due to the presence of these sense organs. There is a greater and greater tendency to look upon the central nervous system as nothing more than a vast mass of communications, whereby both sensory and muscular areas can be brought into relationskip, whereby the simple connecting strands between sensory cell and muscle, isolated in the lower, are bound together in higher animals. The discoveries of Exner compel us to look upon that wonderful plexus of medullary fibres which he has demonstrated in the cortex, as more important even than the nerve cells found there. No one could examine a preparation of the cortex, prepared by Weigert's method, without being convinced that the interlacing fibres to be observed, connected ultimately with every muscle and sensory surface of the body, form a mechanism which will account for our possession both of muscular co-ordination and intellectual assaciation. If at one time certain cells in this intercommunicating meshwork were looked upon as the special seat of sensation and others as the seat of motion, it is impossible so to view them now. As a result of the passage of an impulse through the nervous system, we may have muscular movement and we may have sensation, but in the nervous path through which the impulse passes it is not possible to say that one part is more motor than another, or to localise sensation to any given spot. Every portion of the path receives an impulse which originates in a sensory urea, and passes ultimately to a muscle. Were we to define a sensory cell merely as one that receives an impulse from a sensory surface, and a motor cell as one that transmits an impulse directly to a muscle, we are at once met with a difficulty. The cells in the cortex are on a loop between the sensory and motor cells of the cord, and to which do they belong? It may be inquired, what are then the uses of these cells? It is probable they act as junctions in the nervous network, as suggested by Dr. Hill. They are trophic, and perhaps they act like collections of combustible material placed on a train of gunpowder. In any case it will be advisable to use the terms 
sensory and motor quite tentatively, and preferably to speak of these so-called cortical centres as areas of the nervous system through which pass certain sensori-motor loops, and whose destruction will render impossible the productions of those muscular movements, etc. which had previously depended upon their existence.

Dr. Mercier.

Before entering on this discussion, may I first be permitted to express the sense of incongruity which it arouses? It appears to mo that a discussion by the Neurological Society, as to whether or not the idea of movement is a concomitant of the ontgoing current, bears a certain analogy to a discussion by the Astronomical Society as to whether or not the earth is round.

Dr. Bastian has complained that there has been shown no $a$ priori reason why the generally received doctrine should be preferred to his own, which I with difficnlty refrain from calling the geocentric doctrine of neurology. This is a complaint which he ought not to have the opportunity of making again, and for want of a better I will supply him with an argument wbich is, I hope, not open to objections on the score of deficiency in $\grave{a}$ priori character. The organism exists not alone in space, but in the midst of surroundings. Between it and its surroundings but two actions are passible, viz. action of the surroundings on the organism, and action of the organism on its surroundings. These two actions are of co-ordinate importance. Consciousness cannot exist without both. Life cannot exist without both. Into every manifestation of consciousness and into every manifestation of life buth elements enter as necessary constituents. We may separate them in analysis, but in fact they are inseparable. In the constitution of conscionsness and of life neither of these elements is hefore nor after the other, ifeither is greater nor less than the other. Yet, according to Dr. Bastian, the actions of the environment on the organism are known immediately and directly, while the actions of the organism on the environment are known only mediately and indirectly and subordinately and at second hand.

Much has been said as to whether this or that case has been accurately observed and correctly reported, and as to whether this or that fact may not be capable of a different interpretation from that which Dr. Bastian places on it. I am not concerned to enter on these matters, and I will say at once that I will make Dr. Bastian a present of all his facts. I will take his doctrine as he himself states it, and show, not merely that he has made out no case to be answered, but that he himself explicitly admits the accuracy. and truth of the orthodox viow. 